\title{
Management of Repeat Breeding Syndrome in Cows
}

\author{
Mihai CENARIU*, Emanuel JOSPE \\ ${ }^{1}$ University of Agricultural Sciences and Veterinary Medicine Cluj-Napoca, Romania. \\ 3-5 Calea Manastur, 400372 Cluj-Napoca, Romania \\ *corresponding author: mihai.cenariu@usamvcluj.ro \\ Bulletin UASVM Veterinary Medicine 74(2)/2017 \\ Print ISSN 1843-5270; Electronic ISSN 1843-5378 \\ doi:10.15835/buasvmcn-vm:0045
}

\begin{abstract}
The aims of this study were to identify the status of repeat breeding syndrome (RBS) in a dairy farm, to establish the main cause of RBS and to reduce the number of RBS using the Ovsynch protocol. 20 cows were diagnosed with RBS using computer analysis of the herd and a specific diagnosis for the cause of RBS was attempted. Subsequently, they were divided into 2 groups: cows in group $1(n=10)$ received no hormonal treatment while those in group $2(\mathrm{n}=10)$ were treated using the Ovsynch protocol. Artificial insemination and pregnancy diagnosis was performed in all cows. The $70 \%$ pregnancy rate obtained for Ovsynch showed that the hormonal effect as well as correct timing of insemination had a significant influence on RBS, pointing out towards the managerial factor as one of the main causes of RBS. The cow factor was also included, as endometritis, follicular cysts and anovulatory heats were diagnosed.
\end{abstract}

Keywords: cows, Ovsynch, repeat breeding syndrome

\section{INTRODUCTION}

A cow with repeat breeding syndrome (RBS) is a cow that looks healthy and has a regular estrous cycle, however she will not conceive after three or more sequential inseminations, without any clinically obvious pathological disease (Noakes et al., 2001; Gustafsson and Emanuelson, 2002; Moss et al., 2002). The syndrome is of a major concern in dairy farms because after only a few unsuccessful inseminations cows are culled without further investigation on the cause of RBS (Yusuf et al., 2010).

There are several studies pointing out towards the pathogenesis and consequences of RBS in dairy cattle, their main common point residing in the complex and plurifactorial etilogy of this syndrome (Beam and Buttler, 1999; LeBlanc et al., 2002; Spicer, 2004; Ferreira et al., 2011). The causes of RBS were shown to be often very intricate, but can nevertheless be summarized in short as follows: (1) Management factors: bad timing of insemination, missing heat detection and unprofessional insemination; (2) Semen factors: low quality of semen or infertile bulls; (3) Cow factors (undetected): endometritis, pyometra, mucometra, hydrometra, ovulatory defect, follicular cyst, adhesions, antibodies to seminal antigen, inappropriate uterine involution, infectious diseases, uterine tumours, anovulatory heats; (4) Environmental factors: heat stress, nutritional factor, etc. The correct diagnosis and management of these pathologies is of utmost importance for the veterinary practitioner, which otherwise lead to culling of valuable individuals and therefore great economic loss for the farmer. A well conducted gynaecological investigation is mandatory, taking into consideration all factors that could influence the cows as a group, but also each particular individual situation (Perez-Marin and Espana, 2007).

Several attepts were made to deal with the consequences of RBS by managerial as well as 
therapeutic means, but there are still many aspects to be investigated in order to reveal all facets of this complex syndrome.

The aims of this study were to identify the status of RBS in an Israeli dairy farm by computer analysis of the herd, to reduce the number of RBS using the Ovsynch protocol as well as to establish the main cause of RBS, especially in high yielding cows which produced over 40 litres of milk per day.

\section{MATERIALS AND METHODS}

A total number of 20 Israeli Holstein breed cows, belonging to an Israeli dairy farm were included in the experiment. Israeli Holstein cow is genetically improved, through pairing Holstein Friesian cows with Israelian Demeshk cow, to create what is called today the Israeli Holstein cow. These females were diagnosed with repeat breeder syndrome using computer analysis of the herd as they were shown to have between 6 and 9 unsuccessful inseminations in the past months. The cows were housed in a completely open barn, from all four wind directions for ventilation, with only a roof to block the sun. For every 40 square meters sections of the roof, a 2 meter ventilation fan with a water sprinkler was built, in order to reduce the temperature inside. During summer, before milking, the cows were grouped in the waiting room 30 minutes before milking. They received showers in order to reduce the stress level to a minimum, which helps with the milk quality and quantity. The type of nutrition that cows received was meant to stimulate milk production and was very rigorously mixed in order to meet the nutritional demands of highly lactating dairy cows. Each cow was consuming approximately $45 \mathrm{~kg} /$ day of the following mixture: maize grain $22 \%$, wheat silage $26 \%$, barley grain $5 \%$, wheat grain $1.5 \%$, wheat hay $4.5 \%$, rye grain $5 \%$, alfalfa hay $2 \%$, cotton seeds $1.5 \%$, soybean meal $9 \%$, salt $0.4 \%$, corn gluten feed $4.4 \%$, limestone $1 \%$, rapeseed meal $2 \%$, sunflower meal $3 \%$, urea $1.5 \%$, vitamin premix $0.5 \%$, wheat barn $4 \%$, protected fat $2 \%$, citrus peel $4.7 \%$.

As a regular protocol for the farm that was investigated, cows which were known to have RBS without obvious reproduction pathologies were sent in on every heat for insemination as a normal cow would. After 45 days (in case of no heat signs) they were examined by the veterinarian for pregnancy. In case of negative pregnancy the cows were checked for functional ovaries. This exam would divide cows between those who have functional ovaries (have a corpus luteum or follicle) and those who have "smooth ovaries". For those who had a CL they were treated with PG, usually 2 days later, and were sent for the next insemination with continuous supervision. The cows with "smooth ovaries", if it was their first time presenting this pathology, were treated with $\mathrm{GnRH}$ and were inseminated at the time of heat. In the case of repeat "smooth ovaries" the cows were declared as non-suitable for reproduction. Therefore, when the milk production would drop to a lesser amount (around $25 \mathrm{~L}$ ) the cow was culled.

In our study, a specific diagnosis for the cause of RBS was attempted for each individual, by general clinical investigation, rectal palpation, vaginal examination as well as rectal ultrasonography.

Subsequently, cows were divided into 2 groups according to the method of treatment that was used. Cows in group $1(n=10)$ received no hormonal treatment while those in group $2(n=10)$ were treated with gonadorelin and PGF2alpha, according to the classical Ovsynch protocol. Briefly, the protocol consisted of the following steps: Day 0 - GnRH (1.5 ml Gonabreed, Parnell, USA) at 3pm; Day 7 - PGf2a (2 ml Estroplan, Vetoquinol, Canada) at 3pm; Day 9 - GnRH (1.5 ml Gonabreed, Parnell, USA) at 3pm; Day 10 - insemination first thing in the morning (8 am). Artificial insemination was performed in all cows and pregnancy diagnosis was performed by means of failure to return to oestrus and rectal palpation.

\section{RESULTS AND DISCUSSIONS}

Following our investigations regarding the therapeutic management of repeat breeding syndrome in dairy cows using the Ovsynch protocol, the following results were obtained (Table 1):

As presented above, $70 \%$ of the cows showing the RBS that were treated using the Ovsynch protocol (and therefore timed AI) were diagnosed pregnant 45 days after insemination, as compared to only $20 \%$ in the control group.

In the control group, five out of ten cows were found to have no reproductive pathology, two cows were diagnosed with follicular cysts, and three cows had score 1 endometritis (Figure 1). 
Tab. 1. Comparative results regarding the therapeutic management of RBS in dairy cows between control and treated groups

\begin{tabular}{|c|c|c|c|c|}
\hline Group & $\begin{array}{l}\text { Cow } \\
\text { no. }\end{array}$ & Result of clinical investigation & Cause of RBS & $\begin{array}{l}\text { Pregnancy status } \\
\text { following study }\end{array}$ \\
\hline \multirow{10}{*}{ control } & 1 & No reproductive pathology & Management factors & Not pregnant \\
\hline & 2 & Follicular cyst & Cow factor & Not pregnant \\
\hline & 3 & Follicular cyst & Cow factor & Not pregnant \\
\hline & 4 & No reproductive pathology & Management factors & Pregnant \\
\hline & 5 & Score 1 endometritis & Cow factor & Not pregnant \\
\hline & 6 & Score 1 endometritis & Cow factor & Not pregnant \\
\hline & 7 & No reproductive pathology & Management factors & Not pregnant \\
\hline & 8 & No reproductive pathology & Management factors & Not pregnant \\
\hline & 9 & Score 1 endometritis & Cow factor & Not pregnant \\
\hline & 10 & No reproductive pathology & Management factors & Pregnant \\
\hline \multirow{10}{*}{ treated } & 1 & No reproductive pathology & Management factors & Pregnant \\
\hline & 2 & Follicular cyst & Cow factor & Not pregnant \\
\hline & 3 & Follicular cyst & Cow factor & Not pregnant \\
\hline & 4 & No reproductive pathology & Management factors & Pregnant \\
\hline & 5 & No reproductive pathology & Management factors & Pregnant \\
\hline & 6 & No reproductive pathology & Management factors & Pregnant \\
\hline & 7 & No reproductive pathology & Management factors & Pregnant \\
\hline & 8 & No reproductive pathology & Management factors & Pregnant \\
\hline & 9 & Anovulatory heats & Cow factor & Pregnant \\
\hline & 10 & Score 1 endometritis & Cow factor & Not pregnant \\
\hline
\end{tabular}

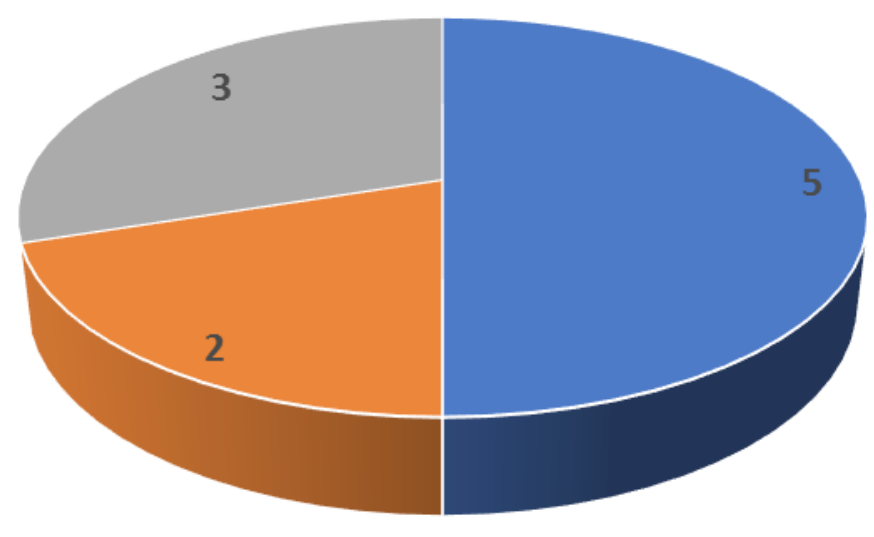

- no reproductive pathology - follicular cyst = score 1 endometritis

Fig. 1. Results of the clinical investigation in group 1 (control) 
In the treated group, six out of ten cows had no reproductive pathology, two cows were diagnosed with follicular cysts, one had score 1 endometritis and one had anovulatory heats (Figure 2).

This data shows that the hormonal effect as well as correct timing of insemination had a significant influence on RBS in this particular dairy farm, pointing out towards the managerial factor as one of the important causes of RBS, as shown previously by other authors (García-Ispierto et al., 2007). The semen as well as environmental factors were ruled out, as cows were inseminated with good quality semen and all cows in the herd were submitted to the same environmental factors, while the cow factor was also included among the reasons of RBS, as endometritis, follicular cysts as well as anovulatory heats were diagnosed.

In this work we found a connection between hormonal status and timing of insemination for a successfull pregnancy in RBS cows. There were several cows which definitely missed the correct timing for insemination or the hormonal level wasn't correct for a successful pregnancy. The Ovsynch protocol helped ensure a correct hormonal status around the ovulation process, together with correct timing of insemination in order to accomplish positive pregnancy. Five out of 10 cows in the control group and six out of ten in the treated group had a repeat breeding syndrome which was influenced by the hormonal misbalance and incorrect timing of insemination, as they had no obvious reproductive pathology that could have represented the cause of RBS. Moreover, a recent study by Sood et al. (2017) demonstrated that part of the RB cows' etiology occurs at an earlier phase of folliculogenesis, thereby impairing oocyte competence, and subsequently reducing the probability of normal fertilization, which diminish embryo vitality and development. Also, Kafi et al. (2017) proved that the ovulatory follicle microenvironment of Holstein repeat breeder heifers places their oocytes at a developmental disadvantage, suggesting the existence of an inherent inferior quality of the ovulatory follicle microenvironment in repeat breeding Holstein heifers.

The rest of the cows in both control and treated group were diagnosed with endometritis, follicular cysts as well as anovulatory heats, which clearly represented the reason behind RBS. The hormonal treatment, as expected, had no result on cows with endometritis, and our study proved the high impact of this disorder on the reproductive performances of dairy cows, as shown previously by other authors (Salasela et al., 2010). More recent studies have even pointed out towards the inflammatory events of endometrial cells in repeat breeder cows. Thus, Wagener et al. (2017) have demonstrated different prostaglandinendoperoxide synthase 2 (PTGS2) and chemokine CXL ligand (CXCL3) mRNA expression between repeat breeder cows and control heifers, which

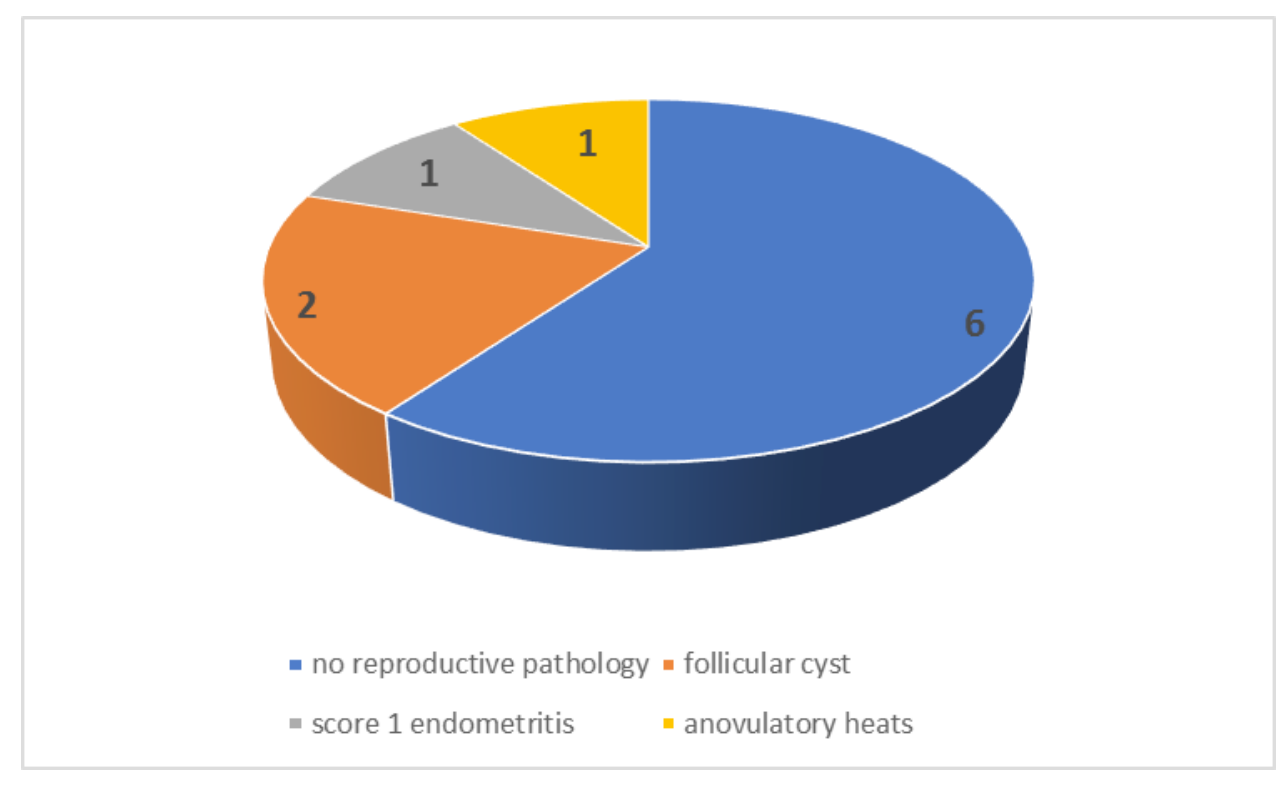

Fig. 2. Results of the clinical investigation in group 2 (treated) 
might be related to subfertility in repeat breeder cows.

Another interesting fact that we could point out from this study was that the number of failed inseminations is not always a true value for the status of an individual cow. Even after 9 failed inseminations in the control group, without any treatment, the $10^{\text {th }}$ insemination was successful (only in 2 cases indeed), which gives us a reason to investigate even deeper for the real reasons of RBS.

In Israel there are 2 different parameters which influence the treatment of RBS, as follows: milk quota (meaning that the farmer is obliged to keep the amount of milk approved from the government according the size of the population in his area) and Kosher milk (meaning insemination cannot be performed on Friday and Saturday and therefore issues regarding the correct timing of insemination will arise). Nevertheless, in this farm, every month there were 10-15 cows which were eliminated from the herd and 25-30 parturitions, so this allowed the farmer to have more flexibility regarding the consequences of RBS.

In Israel, during summertime, milk has got more economical value compared with the winter, and this fact motivates the farmer to control the parturition in the beginning of summer (from June to November). This fact can easily be accomplished by applying the Ovsynch protocol (to maximize parturition in the beginning of summer) and reduce numbers of RBS cows.

\section{CONCLUSION}

The two main reasons of RBS in this study were: the management factor (timing for insemination) and cow factor (ovulatory defect, hormonal misbalance). In order to reduce cases of RBS we recommend the use of Ovsynch protocol and insuring the correct insemination time.

This research did not receive any specific grant from funding agencies in the public, commercial, or not-for-profit sectors.

\section{REFERENCES}

1. Beam SW, Butler WR (1999). Effect of energy balance on follicular development and first ovulation in postpartum dairy cows. J. Reprod. Fert., (Suppl.) 54:411.

2. Ferreira RM, Ayres H, Chiaratti MR, Ferraz ML, Araújo $\mathrm{AB}$, Rodrigues $\mathrm{CA}$, Watanabe $\mathrm{YF}$, Vireque AA, Joaquim DC, Smith LC, Meirelles FV, Baruselli PS (2011). The low fertility of repeat-breeder cows during summer heat stress is related to a low oocyte competence to develop into blastocysts, Journal of Dairy Science, 94(5):23832392.

3. García-Ispierto I, López-Gatius F, Santolaria P, Yániz JL, Nogareda C, López-Béjar M (2007). Factors affecting the fertility of high producing dairy herds in northeastern Spain, Theriogenology, 67(3):632-638.

4. Gustafsson H, Emanuelson U (2002). Characterisation of the repeat breeding syndrome in Swedish dairy cattle. Acta Vet. Scand., 43:115-125.

5. Kafi M, Azari M, Chashnigir O, Gharibzadeh S, Aghabozorgi Z, Asaadi A, Divar MR (2017). Inherent inferior quality of follicular fluid in repeat breeder heifers as evidenced by low rates of in vitro production of bovine embryos. Theriogenology, 102: 29-34.

6. LeBlanc J, Duffield TF, Leslie KE, Bateman KG, Keefe GP, Walton JS, Johnson WH (2002) Defining and diagnosing postpartum clinical endometritis and its impact on reproductive performance in dairy cows. J. Dairy Sci., 85 (9):2223-36.

7. Moss N, Lean IJ, Reid SWJ, Hodgson DR (2002). Risk factors for repeat-breeder syndrome in New South Wales dairy cows. Preventive Veterinary Medicine, 54(2):91-103.

8. Noakes DE, Parkinson TJ, England GCW (2001). Arthur's Veterinary Obstetrics. 8th Edition. WB Saunders.

9. Perez-Marin CC, Espana F (2007). Oestrus expression and ovarian function in repeat breeder cows, monitored by ultrasonography and progesterone assay. Reprod. Domest. Anim., 42: 449-456.

10. Salasela B, Mokhtarib A, Taktazc T (2010). Prevalence, risk factors for and impact of subclinical endometritis in repeat breeder dairy cows. Theriogenology, 74(7):12711278.

11. Sood P, Zachut M, Dekel I, Dube H, Jacoby S, Moallem U (2017). Preovulatory follicle characteristics and oocyte competence in repeat breeder dairy cows. J Dairy Sci., 100(11): 9372-9381.

12. Spicer LJ (2004). Proteolytic degradation of insulin-like growth factor binding proteins by ovarian follicles: a control mechanism for selection of dominant follicles. Biol. of Reprod., 70:1223-1230.

13. Wagener K, Pothmann H, Prunner I, Peter S, Erber R, Aurich C, Drillich M, Gabler C (2017). Endometrial mRNA expression of selected pro-inflammatory factors and mucins in repeat breeder cows with and without subclinical endometritis. Theriogenology, 90:237-244.

14. Yusuf M, Nakao T, Ranasinghe RB, Gautam G, Long ST, Yoshida C, Koike K, Hayashi A (2010). Reproductive performance of repeat breeders in dairy herds. Theriogenology, 73:1220-1229. 